\title{
"Btips" as an Inspiration in Engineering Education and Useful Tool for Solving Problems with Conflicting Constrains
}

\author{
Zbigniew M Bzymek* \\ Department of Mechanical Engineering, University of Connecticut, USA
}

Submission: June 12, 2018; Published: July 18, 2018

*Corresponding author: Zbigniew M Bzymek, Department of Mechanical Engineering, University of Connecticut, Storrs, CT, USA, Tel.: +01-860486-2275; Email: zbigniew.bzymek@uconn.edu

\begin{abstract}
Engineering Problem-Solving process using Information Technology abilities and systems of artificial intelligence has two aspects. It relies on a talent of the designer on one side and the efficiency of the problem solving tools being used on the other. The talent is the attribute of a person. It is very difficult to formalize the talent. No satisfactory formalization has been successfully achieved yet. For this reason during the problem solving process only the real designers' talent and their knowledge and experience are the only things at their disposal. A designer can make several choices, however, and must make a number of decisions that can be made concerning methods, algorithms and software packages. After these initial choices are made, the further problem-solving process can continue to be outlined. The problem-solving method described in this paper is called a BriefTheory of Inventive Problem Solving (BTIPS)and was developed on the basis of TRIZ and TIPS and taughtat the University of Connecticut and at Fairfield University for several years. The application of this method starts with an accurate definition of the problem. The problem has to be properly separated from the environment. Subsequent problem-solving choices depend on the knowledge of the designer, and they include the right sequence of steps, definition of contradictions, choice of solution modules, algorithms, definition of designed systems and subsystems and choice of elements and objects. Then, the designer must select several further paths and make further decisions. These decisions, and the processes following them, should be chosen by the designers. Recommendations for the proper solving path are given in this paper. BTIPS is not only a design and research tool, it also is tremendously useful teaching device. References to current teaching, research, practice and development studies are quoted. This paper is devoted to the characteristics of the BTIPS method and concise information about its use with an emphasis on the newly-added principles of size reduction, miniaturization, nanotechnology and biotechnology. The papers [1,2] and [3] containing knowledge on how to find an ideal solution for a problem with conflicting constrains using BTIPS can be used as additional references.
\end{abstract}

Keywords: Conceptual design; Conflicting constrains; Engineering research; Engineering practice; Education

Abbreviations: BTIPS: Brief Theory of Inventive Problem Solving; GF: Goldfire;IM: Invention Machine;HIS: InformationHandling Services; TO: Tech Optimizer; TIPS: Theory of Inventive Problem Solving; BTIPS: Brief Theory of Inventive Problem Solving; TRIZ: Teoria ResheniaIsobratatielskichZadatsh

\section{Introduction}

Intelligent human actions are based on thinking processes. Those processes consist of two categories: general thinking and problem-solving. In the problem-solving category there are two groups: solving problems whose solutions are generally known but whose specifics have to be developed and solving problems with unknown solutions, that have not yet been discovered. The first category covers problems that differ in size, configuration, and other details from known solutions; these solutions are not new concepts. The second group involves inventive problem-solving approaches that concern new problems whose solutions are not yet known and have to be discovered [4]. In the discovery of unknown solutions, two approaches can be distinguished: psychological [5], and algorithmic [6]. TRIZ [6], Ideation [7], TIPS [8] and BTIPS [9] are algorithmic approaches. BTIPS is a simplified but at the same time enlarged, version of TIPS, and was developed at the University of Connecticut for teaching purposes [10].

\section{Applications}

BTIPS follows IM software BTIPS organization [8] and is composed of three modules: Effects, Principles, and Prediction. This method should be applied in the following way:

i. In the first approach, the designer should look for a phenomenon of nature, science, or technology that would solve the immediate problem. There are many examples of applying Effects including removing sand particles from 
jet engine using the effect of the centrifugal force is one of them [11];

ii. The second approach utilizes Altshuller's observation that majority of inventions are based on the use of a limited number of principles (Altshuller lists 40 of them) that are repeated in many discoveries [6]. In BTIPS there are 44 principles including four additional ones: Size Reduction, Miniaturization, Nanotechnology and Biotechnology;

iii. The third approach is based on the analysis of the contents and the hierarchy of components in the designed system. The designer should rearrange them saving the helpful, eliminating harmful), change any neutral elements into helpful ones and add new helpful components. If after these changes have been made, the designed system still doesn't solve the problem the problem statement should be changed, and the process repeated from the beginning. To save the conceptual work, virtual components may be added with the goal of saving the system until the technology will allow changing the virtual components into physical ones [11].

\section{Conclusion}

With IMTM and TO software [9], BTIPS is a useful tool for teaching, learning, and applying problem-solving methods. It often leads to the Ideal Solution or it points out what necessary inventions are needed in order to get the Ideal Solution. Applying of BTIPS can change an approach and the teaching of engineering conceptual design. The IM and TO systems at UConn are not sufficient support for the developing needs of conceptual design. There is a need for an enhanced public domain software sponsored by a Public Service institution. The software that could be easily approached by high schools, colleges, universities and individual students, practicing engineers and scientists.

\section{Acknowledgement}

Dr. Valery Tsourikov for the supporting of the efforts to start this research; IM Corp. for granting IMTM and TO software; Y Xu and T Lally for research assistance; S. White for software help, K Kornacki for editing.

\section{References}

1. Bzymek ZM, Xu Y (2012) Effectiveness of the Problem-Solving Software in Engineering Conceptual Design. IMECE 2012 - Paper \# 86495.

2. Bzymek ZM (2000) Conceptual product Design Using BTIPS. DEVol.109, recent Advances in Design for Manufacturing (DFM) ASME, pp. 139-147.

3. Bzymek ZM (2005) Brief Theory of Inventive Problem SolvingEnhanced Approach Using Principles. Innovations 2005 (Wing A, et al., eds.), (iNEER), Begell House, United States pp. 503-516.

4. Bzymek ZM (2006) The Quest for the Ideal Solution, Proceedings of Virtual Concept, Playa Del Carmen, Mexico, p. 1-6.

5. Osborn Alexander Fainckey (1963) Applied Imagination. Principles and Procedures of Creative Problem-Solving ( $3^{\text {rd }}$ edn). Charles Scribner's Sons, New York, USA.

6. Altshuller GS (1987) Creativity as an Exact Science: Theory of the Solution of Inventive Problems ( $2^{\text {nd }}$ edn), Gordon and Breach Publishers Inc, New York, USA.

7. (2017) Ideation - General breakdown ideas today" futurethink.com 17 tips \& tricks to get you started.

8. (1995) Invention Machine ${ }^{\mathrm{TM}}, \mathrm{V} .2 .1$ for Windows, Principle, Effects, Prediction", User Guide, IM Corp, Boston, Ma.

9. Bzymek ZM (2012) Engineering Problem Solving -Learning and Practice. ASME IMECE 2012 paper \#88527.

10. Bzymek ZM (2005) New Principles Conceptual Product Design Using BTIPS, Proceedings of the Fifth International Workshop on Advanced Manufacturing Technologies, London, Canada, In: Wang L, Liu XY (Eds.), Sponsored Integrated Manufacturing Technologies Institute, pp. 105-110.

11. Bzymek ZM (2016) A Brief Theory of Inventive Problem Solving (BTIPS) - an Approach to the Engineering Problem Solving in Teaching, Learning and Practice, TRIZ Future Conference "The 16th International Systematic Innovation and Creativity", Wroclaw, Poland.

\section{Your next submission with Juniper Publishers will reach you the below assets}

- Quality Editorial service

- Swift Peer Review

- Reprints availability

- E-prints Service

- Manuscript Podcast for convenient understanding

- Global attainment for your research

- Manuscript accessibility in different formats

( Pdf, E-pub, Full Text, Audio)

- Unceasing customer service

Track the below URL for one-step submission https://juniperpublishers.com/online-submission.php 